\title{
Microspheres and Spheroids: The Value of the Stereomicroscope in Evaluating Damage and Debris
}

\author{
C.L. Cwiklik*
}

*Cwiklik \& Associates, $24006^{\text {th }}$ Avenue South, Ste 257, Seattle, WA 98134 and

Pacific Coast Forensic Science Institute, $24006^{\text {th }}$ Avenue South, No. 256, Seattle, WA 98134

Spheres form when the pressure from all directions is equal. Hollow microspheres resulting from expanding liquids or gasses are observed in conjunction with heat damage [1,2], pyrotechnics [3,4 black powder firearm discharge, various industrial processes, and natural fires. Drop-molded solid microspheres such as glass and metal beads are formed when molten material is dropped through a liquid or a gas such as air. Microspheres can be formed by aerosols such as spray paint or spatter from paint applied by rollers. Even blood droplets may dry into microscopic half-spheres if deposited on non-porous surfaces that interact minimally to disrupt surface tension. Spheroids more irregular than spheres -can be of biological, mineral or synthetic origin. Examples include insect eggs, agglomerates of starch grains, mold spores, beads placed in planting soil to hold moisture, clumps of soot, as well as some desiccants, seeds, and mineral grains. Microspheres and spheroids encountered in forensic casework or contamination studies can span a range of sizes from glass beads and welding beads several $\mathrm{mm}$. in diameter to soot particles that are beyond the resolution of the light microscope. However, the great majority can be seen with the stereomicroscope. Direct deposits of beads of metal from welding can be readily observed on clothing, as can accompanying heat damage to the fabric. Glass beads may be observed microscopically in abrasions or paint smeared on clothing from impact with reflective roadway paint. The use of the stereomicroscope in the classification of the nature and genesis of particulates, and the evaluation of mechanisms of deposits and damage, will be illustrated with several examples.

Metal beads: Metal microspheres may be found in contaminated soil during environmental testing. A site history may help to focus testing, and elemental analysis may provide clues to the source. In one site study [5], soil samples were examined with a stereomicroscope before and after sieving. The stereomicroscope was used to sort and describe particles that were then be grouped into classes and selected for further testing. Nearly 200 individual particles were grouped and described.

Several of the sieved fractions included white paint chips and tiny metal beads and spheroids ranging in size from about $0.15 \mathrm{~mm}$ to $0.50 \mathrm{~mm}$. A site history indicated multiple prior uses including use as a railroad yard and storage of oil in tanks with now-peeling white paint. Six groups of particles were selected for further analysis with SEM-EDX and electron microprobe, with 18 particles from four of the groups found to contain lead. Some of the metal spheres were attributed to babbit metal used in railroad bearings. Microspheroidal aggregates, and tiny particles adhering to non-lead-bearing spheroids, also contained lead.

Microspheres from fiber melt: Nylon, polyester, silk and polyolefins produce tiny beads of melted plastic at the heat-damaged fiber tips, sometimes referred to as nubs. Although most often observed in situ, some of the beads or bubbles may separate from the parent fibers and be found in debris. Such damage occurs not only from fires and radiant heat, but also during normal use and by manufacturing processes such as hot calendering and singeing. In the former, the fabric is passed 
between two rollers under high pressure and one of the rollers is heated. A fabric may be singed to burn off surface fibers [6]. These processes result in tiny nubs, i.e., beading at the fiber tips. Nubs may also result when clothes are ironed or dried at too high a temperature in a domestic or commercial dryer, sometimes with browning of the nubs. It may superficially appear to be a light surface deposit, but is evident as melting when observed with the stereomicroscope. Melted plastic - albeit not spherical - has also been observed as a hard circular deposit of a plastic on the surface of a pair of cotton pants caused by melting of a thin coating on the inner fabric surface, with a ring of melted and beaded and coating peeling away on the inside.

Microspheres from burning of cellulose: Textile fabrics from clothing, rags, and home furnishings are often damaged at fire scenes and by other sources of heat. Material recovered from burn barrels may be examined for metal buttons, zipper teeth, bits of charred fabric, and other evidence of burnt clothing items. When cotton fabrics were burned in tests $[1,2]$ the non-gaseous reaction products include char, ash, mineral residues, an amber-to-brown viscous material, and hollow black microspheres (FIG.1). The amber beads appear to be a condensate, found on less damaged portions of fabric protected by folds (FIG.2). This corresponds with cotton "tar" reported to comprise levoglucosan, its isomers and condensation products [7]. Further thermal decomposition results in hollow black microspheres. When residues are examined microscopically, tiny viscous amber beads are observed adhering to individual fibers, and microscopic hollow black spheroids shaped like the amber beads are observed on the burnt fabric and are plentiful in sieved debris from the burn. White spheres of carbonate - a reaction product of cellulose decomposition - may also be observed.

[1] C.L. Cwiklik and M.J. Dean, Proceedings of the AAFS 2008 meeting, paper no. C62.

[2] C.L. Cwiklik and K.J. Wilberding, Proceedings of the AAFS 2010 meeting. paper no. A117.

[3] K.L. Kosanke et. al., J. Forensic Sci., 2006, 51(2), 296-302

[4] K.L.Kosanke et. al., J. Forensic Sci., 2003, 48(3), 531-537

[5] J.L. Iem et. al., Proceedings of the AAFS 1999 meeting paper no.C21.

[6] Deedrick, D.W., in Houck M., ed., Mute Witnesses: Trace Evidence Analysis, Academic Press, London and San Diego, California, 2001, pp. 1-20.

[7] F. Shafizadeh, Pure Appl. Chem 55:4 pp 705-720, 1983.

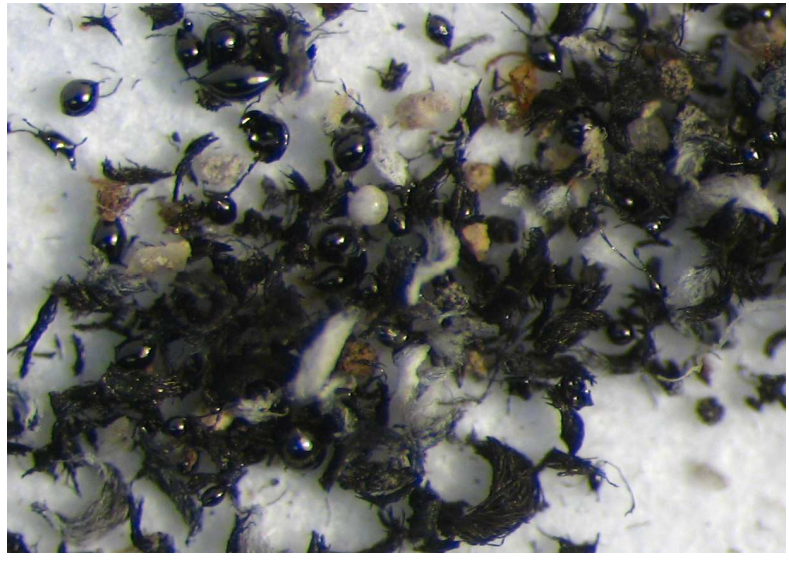

FIG. 1. Sieved debris from bluejean burn, $>300$ mesh: hollow black spheroids, white carbonate spheres, ash, and char

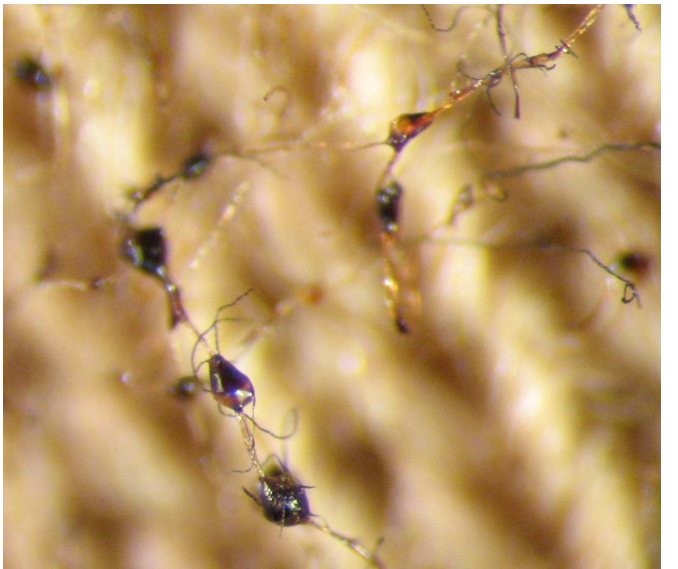

FIG. 2. Black, brown and amber droplets adhering to fibers in unburnt fold in charred cotton rag 